\title{
ENCONTRADO UM INCUNÁBULO QUE PERTENCEU A CABRAL.
}

\author{
NICOLAU DUARTE SILVA \\ do Instituto Histórico e Geográfico de São Paulo.
}

Na tarde de 19 de novembro de 1968, durante a visita de descendentes de Pedro Álvares Cabral ao Instituto Históiico e Geográfico de São Paulo, a que pertencemos há cêrca de quarenta anos, havendo mesmo exercido a sua primeira vice-presidência, tivemos permissão para falar, no espaço de cinco a dez minutos, à margem do programa pré-estabelecido.

Foi, evidentemente, uma concessão do presidente do sodalício, acadêmico Aureliano Leite, tendo em vista os objetivos da nossa missão, que era a de apresentar, como fato inédito, provas materiais da existência de um livro de Cosmografia, edição de Salamanca, de 1498, que pertenceu ao descobridor do Brasil.

No desempenho de nossa tarefa, além de exibirmcs fac símile das partes do cimélio com o fro itispício da obra em que figura o autógrafo de Cabral (Pedro Álvares Cabral) e um apontam.nt nuscrito, supostamente da época, antecedendo um monograma, em carimbo, com as letras "D C" (Duque de Cadaval?), sob uma corôa, conforme cliché ilustrativo, pronunciámos algumas palavras, dentro do limite de tempo de que dispúnhamos.

Registrando-as aqui, nestas breves linhas, desejamos ap nnas documentar o fato, pois o acesso ao precioso incunábulo de 1498, que pertenceu a Cabral, brevemente será, como esperamos, per xitido aos estudiosos, através do microfilme em nosso poder, tudo dependendo das diligências, aliás muito animadoras, que estamos promovendo junto aos seus aforturados possuidores.

Felizmente, para alcançarmos os nossos objetivos, de pura pesquisa científica no campo da História, contamos com o apôio de espíritos bem formados, o que representa, certamente, uma garantia para os verdadeiros historiadores e um confôrto para o autor destas palavras. 
Mas, qualquer que seja o desfâcho do acontecimento, com a nossa maior ou menor participação pessoal, esta simples comunicação, através das prestigiosas páginas da "Revista de História", já nos compensará, suficientemente, pelos esforços que vimos dispendendo, há algumas dezenas de anos, para obter a mencionada documentação cabralina .

Agradecendo a quantos honraram o ato com a sua presença, transcrevemos, a seguir, a exposição a que nos referimos.

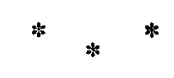

\section{HÁ UM LIVRO DE 1498 NO CAMINHO DE CABRAL.}

Em 1929, sendo redator de assuntos históricos do jornal "Correio Paulistano", publicávamos, em sua edição de 3 de maio, um artigo sob o título "O descobrimento do Brasil 1500-1929".

Já naquela época possuíamos, como ferramenta de trabalho, uma biblioteca constituída não sòmente de obras de História, pròpriamente dita, mas também de suas ciências auxiliares. Entre estas não faltava a parte bio-bibliográfica, que jamais deixou de merecer a nossa atenção.

Pois bem. Ao Jançarmos aquêle nosso artigo de 1929, já sabíamos da existência de um livro com a assinatura de Pedro Álvares Cabral, livro êsse da espécie incunábulo, pois foi impresso antes do ano de 1500 .

Entretanto, como não seria prudente chamar a atenção para o cimélio, sem condições de adquirí-lo, dado que era anunciado há anos, por uma livraria da Europa, pela quantia de 375 libras esterlinas, elevada para a época, resolvemos aguardar uma oportunidade.

Em dado momento, em julho de 1961, dirigindo-nos aos seus possuidores, não fomos felizes. A carta registrada que lhes enviamos nos foi devolvida, em setembro do mesmo ano, com a informação internacionalmente adotada pelos Correios Inconnu .

Confessamos que não foi pequeno o nosso desapontamento, ao ter que considerar, pelo menos temporàriamente, perdido o precioso incunábulo.

Em pleno 1968, em meio às festas programadas em homenagem à memória de Pedro Álvares Cabral, vem-nos dos Estados Unidos, endossada pelo New York Times e aqui veículada pelo "O Estado de São Paulo", a notícia de que "Há uma pedra no caminho de $\mathrm{Ca}-$ bral". 


\section{Eolmographia pomi poni cum figuris.}

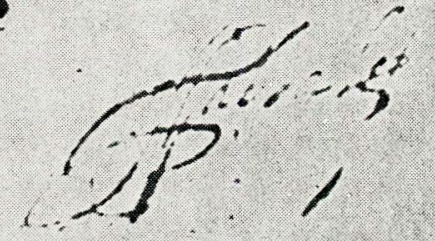

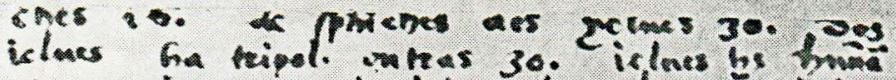

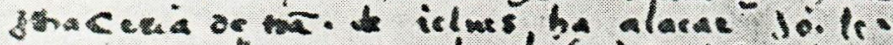

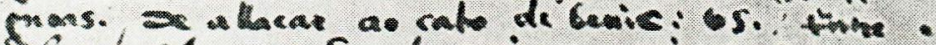

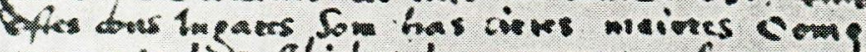
ture nipd te fliches has moneers. fonnw dus Cievs maivers shabe anple wi melildia. epan her enentes de dice onde be bermple, do jupine. atcours.

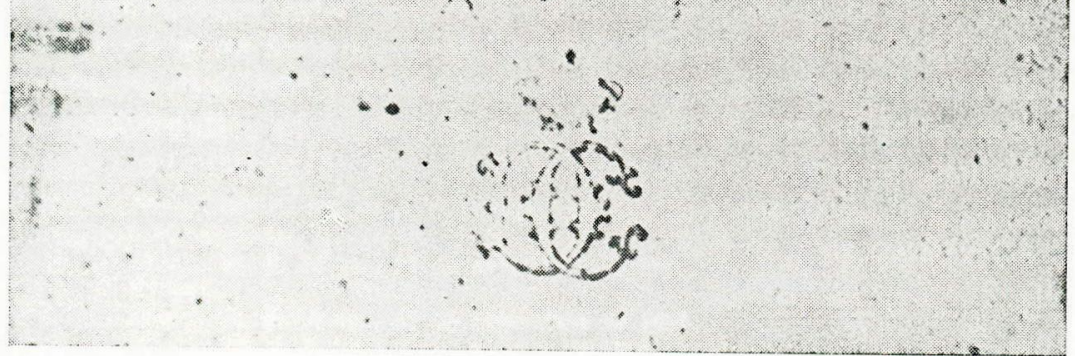


O jornalista Walter Sullivan, chefe da seção científica do grande jornal norte-americano, escudado no professor Cyrus Gordon, da Universidade de Brandeis, em Waltham, Massachusetts, voltava a tratar da suposta vinda de fenícios à América antes de Cabral e anunciava a existencia de uma pedra com inscrições tenícias no Brasil, como testemunho de sua afirmação.

Em minuciosa entrevista para o jornalista Luiz Nogueira, do "Jornal do Brasil", publicada no dia 17 de agôsto de 1968, tivemos oportunidade de esclarecer o assunto, provando que tudo nã s passava da reedição de uma fraude científica de cêrca de um século de existência, e que tanto preocupara a Ladislau Neto, saudoso diretor do Museu Nacional do Rio de Janeiro, sua primeira vítima, nos anos de 1872 a 1885 .

Nessa altura, prosseguindo em nossas pesquisas para encontrar o almejado livro cabralino, conseguimos localizá-lo nos Estados Unidos e dêle obter a competente cópia em microfilme.

Estamos, assim, em condições de afirmar, parodianto a suposta existência de que "Há uma pedra no caminho de Cabral", que o que realmente existe é um incunábulo de 1498 na vida do descobridor do Brasil .

E, se nos fôsse permitido um gracejo, para amenizar a aridez desta nossa exposição, nos proporíamos a negociar a troca da suposta pedra fenícia do Brasil pelo cimélio de Pedro Âlvares Cabral dos Estados Unidos.

Dispondo de pouco tempo, não podemos entrar em pormenores a respeito das nossas diligências para encontrar o valioso incunábulo, nem acêrca da importância cultural da obra e do lugar que ainda hoje ocupa em nossos meios científicos. Isso ficará para ocasião mais oportuna.

Mas, ainda assim, não será demais declarar que se trata de uma edição espanhola, porém em latim, da "Cosmografia" de Pomoonius Mella, de Salamanca, de 1498, com duas xilogravuras. Intitula-se: Cosmografia pom ponii cum figuris. Além da assintura de Pedro Álvares Cabral, apresenta notas manuscritas e um monograma, em carimbo, com as letras "D C" sob uma corôa.

Sua importância não está apenas no assunto da obra, de que existem exemplares espalhados pelo Mundo, anteriores e post riores ao ano de 1498 . Seu mérito reside no fato de haver pertencido ao descobridor do Brasil, de que apresenta a competente assinatura, afiançada por uma das mais respeitáveis e prestigiosas livrarias do mundo.

Aqui, no Brasil, na Biblioteca Nacional do Rio de Janeiro, há dois exemplares da mesma, arrolados por d. Rosemarie Erika Horch, 
num precioso lote de 187 incunábulos. Um de Veneza de 1482 e outro de Salamanca de 1498, êste idêntico ao de Cabral.

O professor Joaquim Barradas de Carvalho, da cadeira de História da Civilização Ibérica da nossa Univercidade da Sĩo Paulo, teve oportunidade de compulsar mais de uma cópia dêles, inclusive a de Salamanca de 1498, em suas pesquisas feitas em Port:g gרl. Espanha e França, "com o auxílio material da Fundação Calouste Gulbenkian". E' o que declara em trabalho recentemente reunido em volume, com o título de "As fontes de Duarte Pacheco Pereira no Esmeraldo de Situ Orbis".

Tudo isso é sabido dos nossos estudiosos, inclusive que era o livro de cabeceira do mencionado Duarte Pacheco Pereira, que o utilizava na tradução que ainda hoje existe em m'n'ıscrito, aguard ndo editor, em Portugal, na Biblioteca da Ajuda, e que enriqueceu de anotações.

Também não se ignora que tal tradução é atribuida ao célebre Mestre João, físico del Rei D. Manuel de Portugal e companheiro de Cabral na viagem descobridora de 1500 , identificado com o espanhol João Faras.

Não seria de admirar que o nosso exem lar, em latim, de Salamanca, de 1498, pudesse ser o mesmo utilizado nəquela tradיç̃̃o, e que também houvesse sido manuseado por ambos. Cabral e Mestre João, durante a segunda exnedicão portuguêsa à India e de que resultou o descobrimento do Brasil!

Mas, a partir de agora, muitas e muitas suposições e conclısões surgirão. Aguardêmo-las, na certeza de que algo de nôvo enriquecerá a vida tão obscura do filho do "Gigante da Beira". 